IBIMA Publishing

Advances in Cancer Research \& Treatment

http://www.ibimapublishing.com/journals/ACRT/acrt.html

Vol. 2014 (2014), Article ID 515011, 14 pages

DOI: $10.5171 / 2014.515011$

Research Article

\title{
Conventional, Doppler Ultrasound and Real Time Elastography in Diagnostic of Thyroid Solitary Nodules
}

\author{
Stoian Dana ${ }^{1,2}$, Mihaela Crăciunescu ${ }^{3}$, Lazar Fulger ${ }^{4}$, Diana Anastasiu² and \\ Marius Craina ${ }^{2}$ \\ ${ }^{1}$ CentrulDr.D - Endocrinology, Elastography, Timisoara, Romania \\ ${ }^{2}$ Department of Obstetrics Gynecology, University of Medicine and Pharmacy “Victor Babes", \\ Timisoara, Romania \\ ${ }^{3}$ Department of Microbiology, University of Medicine and Pharmacy “Victor Babes", Timisoara, \\ Romania
}

${ }^{4}$ Department of Surgery, University of Medicine and Pharmacy "Victor Babes", Timisoara, Romania

Correspondence should be addressed to: Stoian Dana; drd@centruldrd.ro

Received Date: 16 November 2013; Accepted Date: 19 February 2014; Published Date: 13 May 2014

Academic Editor: Patricio Cabané T.

Copyright (C) 2014 Stoian Dana, Mihaela Crăciunescu, Lazar Fulger, Diana Anastasiu and Marius Craina. Distributed under Creative Commons CC-BY 3.0

\begin{abstract}
In the presence of a solid thyroid nodule, the therapeutically approach is imposed by the probability of a malignancy. Ultrasound is considered to be "the" imagistic diagnostic tool, and the golden standard is represented by the FNAB. US elastography is currently used in differentiation of malignant from benign lesions.
\end{abstract}

This prospective study included 112 patients, mean age 52.08 \pm 11.43 years, 65 females and 47 men, with solitary thyroid nodules on conventional US, with a volume higher than $0.50 \mathrm{ml}$. Complete ultrasound evaluation was performed for each case: gray scale, Doppler and strain elastography. All patients underwent surgery after complete evaluation. Extemporaneous and postsurgical histopathological exam were performed in all cases.

We identified 19 cases with cancer and 93 benign lesions. We calculated the diagnostic value for each ultrasound parameter, and we saw that some parameters are significant in diagnosing thyroid malignancy: irregular margins (AUC $=0.761, \mathrm{p}=0.00001$ ), taller than wide (AUC = $0.723, p=0.0001$ ), positive calcification (AUC $=0.7416, p=0.0001$ ), absent halo sign (AUC = $0.717, \mathrm{p}=0.0001$ ), extracapsular invasion (AUC $=0.684, \mathrm{p}=0.0012$ ). The presence of 4 suspect signs increases diagnostic quality (AUC $=0.8529, \mathrm{p}=0.000$ ), and combined evaluation US-2B and Doppler have even better results (AUC $=0.8985, \mathrm{p}=0.00001$.

Cite this Article as: Stoian Dana, Mihaela Crăciunescu, Lazar Fulger, Diana Anastasiu and Marius Craina (2014), "Conventional, Doppler Ultrasound and Real Time Elastography in Diagnostic of Thyroid Solitary Nodules," Advances in Cancer Research \& Treatment, Vol. 2014 (2014), Article ID 515011, DOI: $10.5171 / 2014.515011$ 
Nevertheless, diagnostic quality of RTE is higher than all separate or combine conventional ultrasound evaluation: $\mathrm{AUC}=0.99, \mathrm{p}=0.0001$

RTE color map screen is a useful tool in discriminating solitary thyroid masses.

Keywords: Solitary thyroid nodule, real-time-elastography, thyroid cancer.

\section{Introduction}

As Lazar F (2008) describes, cancer suspicion should be present in the presence of any thyroid nodule, thyroid nodule being the most frequent form of manifestation of differentiated thyroid carcinoma. Even if our region is an iodinereplete area, as states by Ghelase et al. (2007) thyroid nodules are a common pathology in our region. The prevalence is high, they are found clinically in $4-8 \%$ of cases, as in the paper of Hegedus et al. (2004), much higher, as Frates et al. (2005) describes, $19-55 \%$ with the use of ultrasound even higher, described by Harach et al. (1985), up to as high as 50\% in autoptic studies.

Clinical signs in nodular thyroid pathology are specific, but only important thyroid masses are associated with compressive symptomatology. The dilemma of small thyroid masses, described by Papini et al. (2003) is the lack of specific clinical signs, but despite of this, Tan et al. (1995) recommend proper inspection, and palpation of the gland should be done. Regardless compressive symptoms, thyroid dysfunction signs or cosmetic reason, The Study Group of Korean Society of Radiology (2011) recommend the main goal for the clinician, the correct identification of the malignancy, even in small thyroid nodules.

The goal of the modern investigation techniques is to discriminate with as high as possible sensitivity and specificity suspicious from unsuspicious thyroid nodules. In the Romanian experience, Lazar F (2008) describes a sensitivity of up to $60 \%$ for the fine needle aspiration biopsy (FNAB) in diagnosing thyroid malignancy. Patient compliance and a trained thyroid cytologist are the most frequent limitation of the method. Tan et al. (1995) considers ultrasound to be the most sensitive noninvasive diagnosis tool of the thyroid nodules. There is no consensus regarding the importance of US in selecting the cases for FNAB, guiding the procedure or followup US criteria, or using US as a screening tool for thyroid cancer detection Tan et al. (1995), Moon et al. (2011), ATA Guidelines Task Force (2009) and AACE Guideline (2006).

Many authors, recommend some characteristics to be followed: size, echogenicity, composition of the nodule, presence or absence of calcification/halo/irregular margins and also blood flow pattern, presence and aspect of micro-calcification and also the characteristics of the strain elastography, as described by Tan et al. (1995), American Thyroid Association Guidelines (2009), Leenhardt et al (2011), Stoian et al (2012).

As described in a previous paper, Stoian in 2012 considers elastography is used complementary to classical gray scale and Doppler US, for improving the diagnosis of thyroid tumors, which appear harder than the surrounding tissue. The EFSMUB Guidelines (2013) stated that tissue that is found hard on elastography scan is closely correlated with malignant disease. The results of previous studies, Stoian et al (2012), Crosgrove et al (2013), Asteria et al. (2008) and Rago (2007), are mostly encouraging, showing a very high sensitivity (82-97\%) and specificity (97$100 \%$ ) of malignancy diagnosis in hard nodules. There are also some negative results, as the results of Lippolis et al. (2011) with low specificity of the method: intermediate cellularity might be associated with an increased strain, respectively some cancers cases are not an elastic, so are with normal, benign type color map results.

Seeking a noninvasive, repetitive, high compliance method in differentiation benign versus malign thyroid nodules, is 
the normal approach of each clinician involved in the thyroid diagnostic field.

\section{Material and Method}

\section{Patients}

The study is a preliminary stage report. We analyzed cases seen in the Endocrinology Office, Center Dr. D, affiliated with the University of Medicine and Pharmacy "Victor Babes" Timisoara, in the period January 2011- January 2013. We included only cases with solitary thyroid nodules, predominantly solid, with volumes higher than $0.50 \mathrm{~mL}$. All of the patients underwent surgery in the Surgical Department of County Hospital, member of the same University. All patients gave their inform consent to the approach. In the over mentioned time spam, we identified 145 cases that matched to the inclusion criteria: solitary solid thyroid nodule. The surgical intervention was accepted and done by the time of data analyses only for 112 cases out of the 145 ones (77.24\%). The study group comprised 85 females, mean age $51.11 \pm 10.51$ years, and 27 men, mean age $54.08 \pm 12.43$, mean age in the study group $52.08 \pm 11.43(95 \% \mathrm{LCL}=45.86$ years $95 \%$ UCL 55.60 age) range 24 to 74 years with confirmed thyroid solid nodules. All these112 patients were included in our analysis.

\section{Equipment}

We performed the ultrasound evaluation of each patient on a Hitachi EUB $7500 \mathrm{HV}$ machine with 6-13 MHz variable frequency linear probe, with Doppler and elastography software, with recording of frames of all lesions prospectively on color elastography color map 1 (red-yellowgreen-blue color map); Hitachi Medical System, Tokyo, Japan.

\section{Conventional, Power Doppler US and Elastography}

Preoperative, all patients were examined by the same operator (D.S.), using High Resolution B-mode grey scale ultrasonography (US), Power Doppler ultrasonography (PD) and Real Time ultrasound strain elastography (USE) using the same machine. We analyses at each nodule the following parameters, used also by Thyroid study Group of Korean Society of Radiology (2011): echogenity (hyper-, iso and hyperecoic compared to the normal thyroid parenchyma); halo phenomena (presence or absence); irregular or well defined margins, shape (dominant dimension); intranodular homogeneity; extracapsular extension; presence of calcification: spot micro calcifications: hyperechoic spots less than $2 \mathrm{~mm}$, without acoustic shadowing, macrocalcifications round solitary/eggshell or nonspecific calcification.The paper of Gao et al. (2011) defines different patterns for color flow Doppler: absence of any blood flow, perinodular with no or scare intranodular blood flow, marked intranodular blood flow or unique dominant intranodular vessel. Additional malignant changes in the regional limfnodes were also evaluated, as recommended by the Thyroid study Group of Korean Society of Radiology (2011).

The US elastography was performed during the same US examination, by the same observer. The US elastograme valuated qualitatively, as usual, over de $2 \mathrm{~B}$ map, with the scale ranging from red - soft tissue to blue - hard lesions with no strain. The compression applied to the neck was always between double-checked by the standardized real-time measurement displayed on the screen. Bamber et al. (2013) recommend the use of moderate pressure with the scale 3 to 4 for the analysis. This is required because the extent of tissue compression influences both the tissue response and the elasticity score. The images were classified by the UENO 5 point scale (19): ES $1=$ soft, elasticity (green color) within whole lesion, ES 2 = soft, elasticity (green color) in more than $50 \%$ of the lesion, especially in the center, ES 3 = intermediate, blue in circa $50 \%$ of the area predominant in the center of the lesion (elasticity only at the periphery of the nodule), ES $4=$ hard, no elasticity, predominant blue color, ES 5 = no elasticity in the nodule and surrounding area. Examples are presented in the following images: Fig.1 and Fig.2 and Fig. 3. 


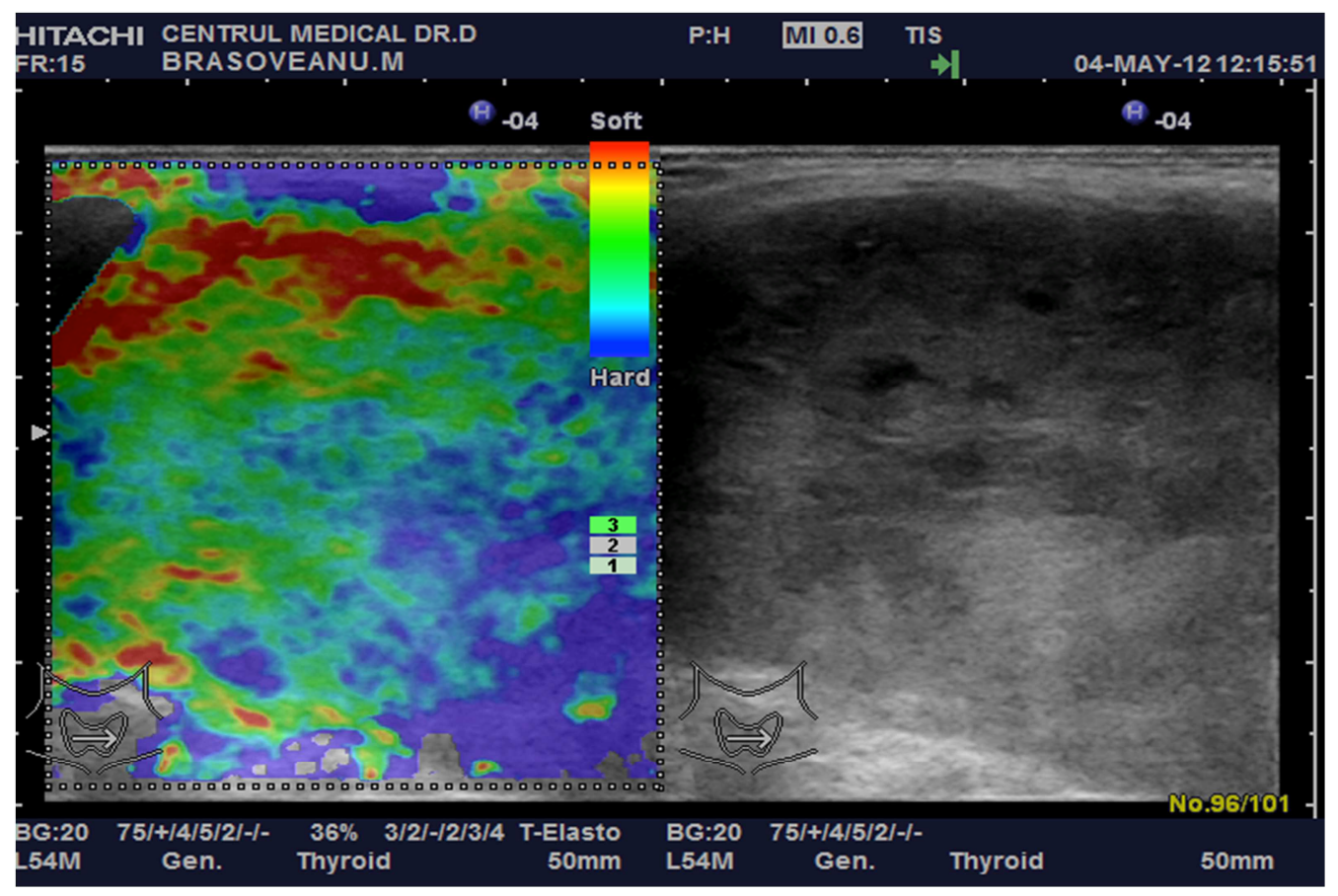

Figure 1: Images from a 65-Year- Old Women, with A 11.2 Ml Solitary Thyroid Nodule, with Hypoechogenicity, Oval, Well Defined Margins, No Calcifications, No Extracapsular Invasion, Scare Intranodular Vascular Signal, with RTE 3 Scale. The Patient Had FNAB, with Benign (Bethesda 2) Result. Histopathological Results Showed a Papillary Microcarcinoma with a $5 \mathrm{Mm}$ Diameter.

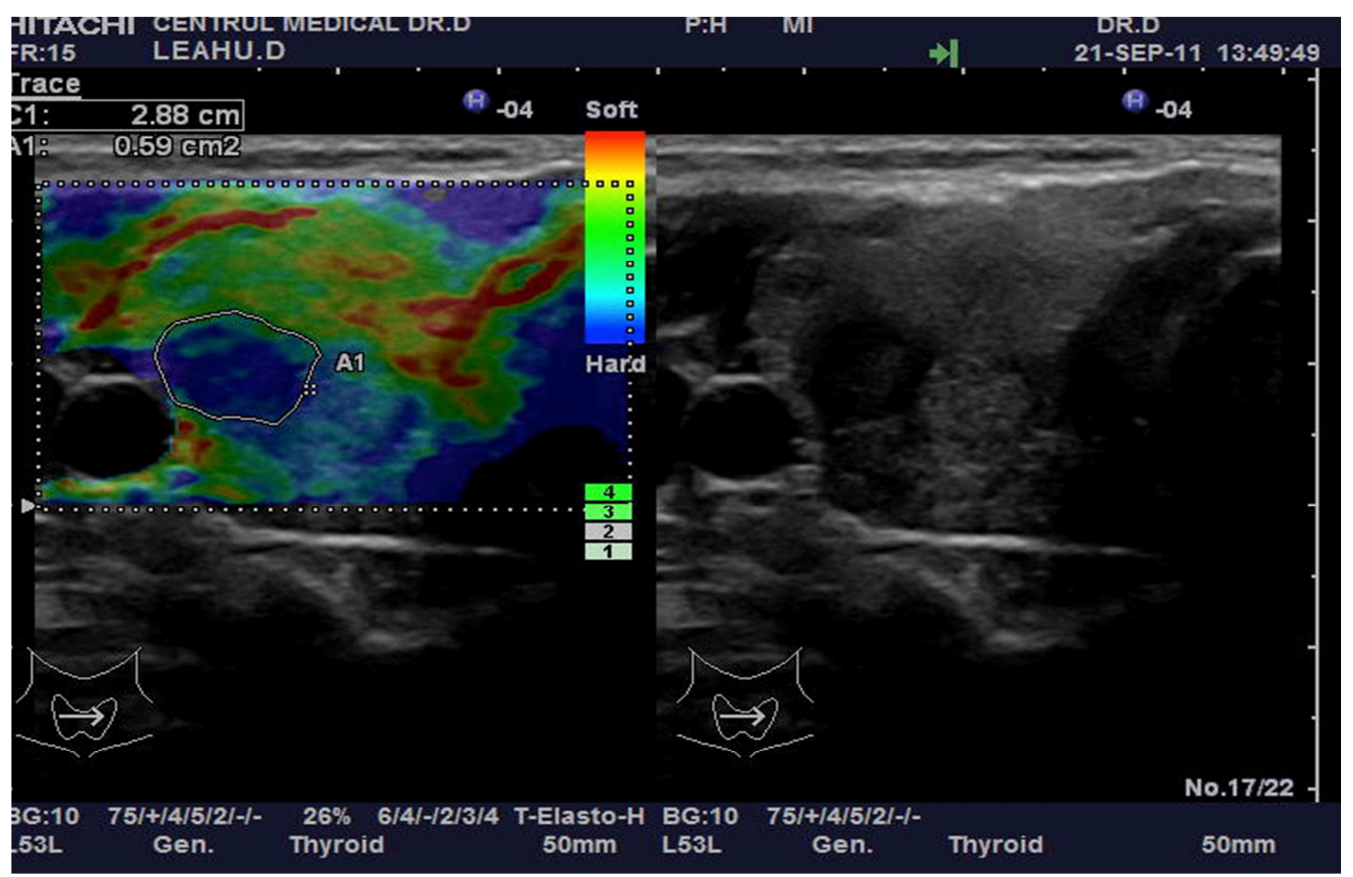

Figure 2:A Case of a 41 Year Old Woman, with a Small Solid Nodule, Round, Solid, Intense Hypoecogenicity, Irregular Margins, No Calcifications, Important Intravascular Signal RTE 4 Scale. No FNAB. Histopathological Report: Papillary Carcinoma. 


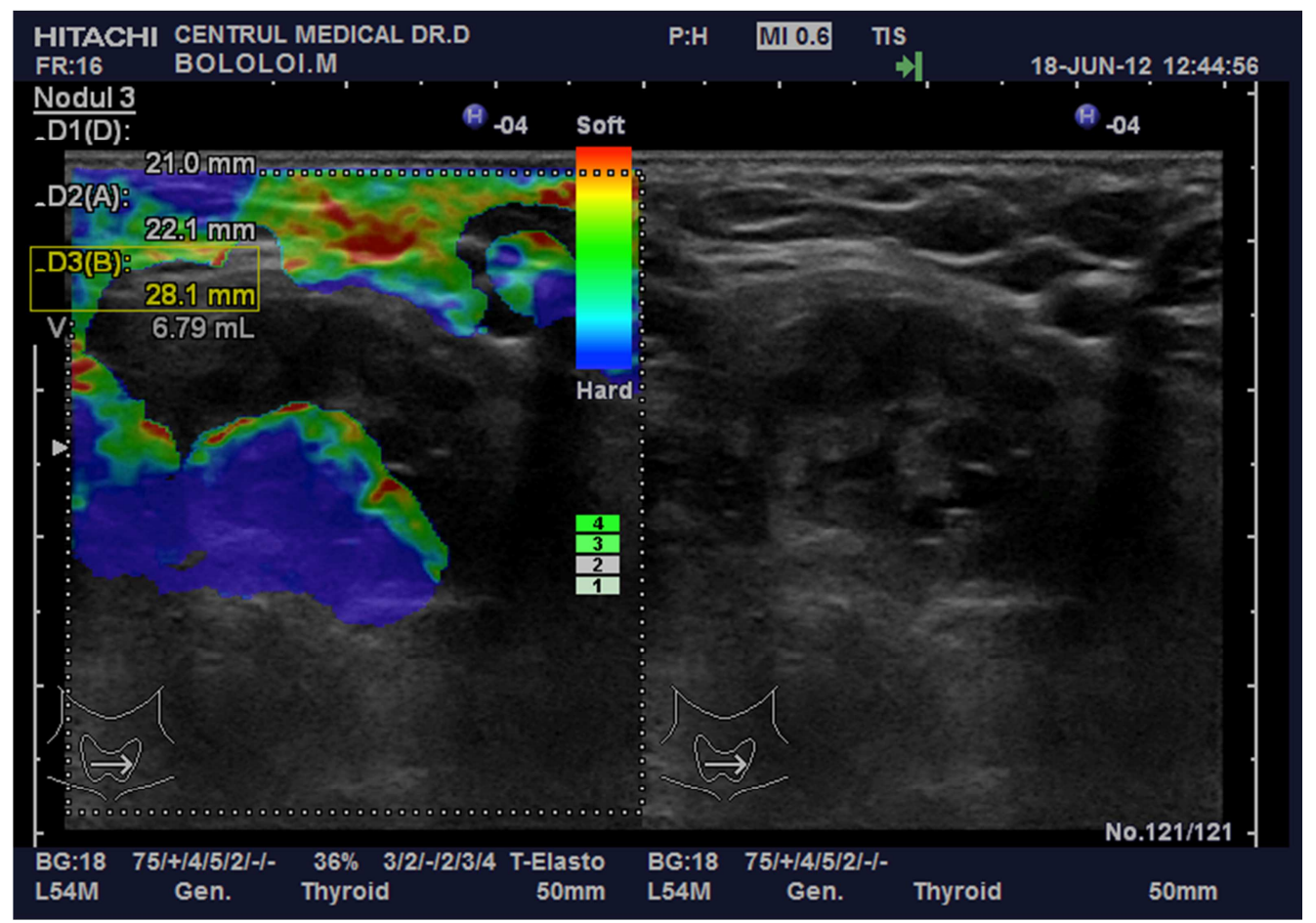

Figure 3: Images in a 67-Year-0ld Woman with an Old Goiter, with Compressive Symptoms. Ultrasound Revealed a 6.79 Ml Solitary Right Solid Thyroid Nodule, Oval, Well Margins, with Discrete Hypoecogenicity, Incomplete Halo Sign, No Capsular Involvement, Intranodular Calcification, Intravascular Vascularization RTE Score 5

FNAB showed Bethesda 3. Total thyroidectomy was performed and classic papillary thyroid carcinoma was confirmed after the surgery.

\section{FNAB}

We performed FNAB guided by the ultrasound in 57 out of the 112 cases. We used $30-40 \mathrm{~mm} 23 \mathrm{G}$ needles, no anesthetic procedure. The other 55 cases were: to small (diameter under $1 \mathrm{~mm}-26$ cases), pre-carotidian position (11 cases), or noncompliant patients (18 cases).Cytological diagnostic was made according to the Bethesda Classification.

\section{Treatment}

All patients with predominant solid nodules (112 cases) were referred to surgery. The surgical protocol was: in cases with no suspicious findings - total lobectomy on the site of the nodule, respectively in cases with suspect lesions, total thyroidectomy was performed as a principle. Suspect findings were considered: positive FNAB results (Bethesda 4, 5, 6), increased nodular volume over $3 \mathrm{~cm}^{3}$, egg shell calcifications, $\mathrm{ES}=4$ and 5 cases, regardless the nodular volume.

All excised pieces were sent to the Histopathological Department.

\section{Histopathological Diagnosis}

Each piece extracted from each case was formalin-fixed and paraffin embedded both nodular and apparent healthy thyroid tissue. The histological diagnosis was made by the pathologist on duty, on the day of surgery, according to the World Health Organization Guidelines described in 1974 by Heidinger and Sobin. In selected cases, imunohistochemical reactions were performed: HBME, CH-19, K067 and TTF. 


\section{Statistical Analysis}

Numerical data (age, TSH value, and nodule volumes) are shown in median, minimum, maximum and 95\% LCL and 95\% UCL levels. Compared results were obtained with the Student's $t$ test two sample technique. The diagnostic performance of different parameters was evaluated by Receiver Operating Characteristics (ROC) curve. Sensitivity, specificity, PPV, NPV were calculated for each diagnostic parameter. P-values less than 0.005 were considered as statistically significant. The results from the histopathological report were considered as golden standard results. Analyses were carried out with NCSS software version NCSS PAAS 2008 v8.0.11.

\section{Abbreviations}

$\mathrm{BN}=$ benign nodule

$\mathrm{CA}=$ cancer

ES = elastography scale

FTC $=$ follicular thyroid cancer

LCL = lower confidence level

MTC $=$ medullar thyroid carcinoma

$\mathrm{NPV}=$ negative predictive value

PPV = positive predictive value

PTC = papillary thyroid cancer

ROC $=$ receiver operating characteristics

$\mathrm{RTE}=$ real time elastography

$\mathrm{TSH}=$ thyreotrop hormone

UCL = upper confidence level

US = ultrasound

\section{Results}

\section{Histology}

Of the 112 patients, $19(15.94 \%)$ had a final diagnosis of thyroid malignancy on histology: 16 cases (84.21\%) papillary thyroid carcinoma: 3 classical variant, 9 follicular variant, 2 micro carcinoma and 2 macrofolicullar variant, 1 case $(5.26 \%)$ of one undifferentiated carcinoma, 1 case (5.26\%) of follicular thyroid cancer and 1 case $(5.26 \%)$ of medullar carcinoma.

From the 93 benign cases $(84.06 \%)$, we had 39 follicular adenoma, 11 hyperplastic nodules, 12 aniso-follicular nodules colloid cystic degenerative changes, 18oxyphilic adenomas (with dysplasia or metaplasia), 9 chronic autoimmune thyroiditis with no other associated lesion and 4 parathyroid adenoma.

\section{Conventional Ultrasound}

We described and quantified the same set of parameters in each nodule: conventional ultrasound, Doppler and strain elastography. All data regarding ultrasound characteristics are described for this number of cases. The numerical parameters values in benign (BN) and malignant (CA) nodules are presented in Table I. The cancer prevalence in the study group was $18.82 \%$ in female patients (16/85 cases), respectively $11.11 \%$ in the males patients $(3 / 27$ cases).There was no significant difference regarding age $(\mathrm{p}=0.07)$, thyroid functional level $(\mathrm{p}=0.23)$ or nodule volume $(\mathrm{p}=0.06)$ between benign and malign cancers when assessed with equal variance $\mathrm{T}$ test. 
Table 1: Differences in Age, Tsh Value, Nodule Volume and Nodule Number in Cases with Benign Lesions (BN) versus Cancer (CA)

\begin{tabular}{|l|l|l|l|l|l|}
\hline Parameter & Mean & SD & SE & 95\% LCL & 95\% UCL \\
\hline Age (years) & & & & & \\
\hline BN & 52.63 & 11.21 & 1.22 & 49.16 & 53.50 \\
\hline CA & 51.11 & 12.43 & 3.23 & 41.51 & 53.38 \\
\hline TSH (UI/mL) & & & & & \\
\hline BN & 1.615 & 1.28 & 0.142 & 1.482 & 1.978 \\
\hline CA & 1.578 & 0.871 & 0.172 & 1.132 & 1.975 \\
\hline $\begin{array}{l}\text { Nodule volume } \\
\text { (ml) }\end{array}$ & & & & & \\
\hline BN & 2.65 & 1.625 & 0.638 & 2.52 & 5.06 \\
\hline CA & 4.510 & 2.45 & 0.356 & 1.71 & 11.70 \\
\hline
\end{tabular}

The diagnostic characteristics of the followed parameter in conventional ultrasound are presented in Table 2. The prediction of each parameter in differentiating benign versus malign lesions is also presented in Table 2.

Table 2: Predictivity of Thyroid Us Parameters in Diagnosing Carcinoma (CA) versus Benign Lesion (BN)

\begin{tabular}{|c|c|c|c|c|c|c|c|}
\hline Parameter & Detail & $\begin{array}{l}\mathrm{BN} \\
(\mathrm{n}= \\
93)\end{array}$ & $\begin{array}{l}\mathrm{CA} \\
(\mathrm{n}=19)\end{array}$ & $\begin{array}{l}\text { Sensitivity } \\
(\%)\end{array}$ & $\begin{array}{l}\text { Specificity } \\
(\%)\end{array}$ & $\begin{array}{l}\text { PPV } \\
(\%)\end{array}$ & $\begin{array}{l}\text { NPV } \\
(\%)\end{array}$ \\
\hline \multirow[t]{2}{*}{ Shape } & Oval & 69 & 5 & 26.31 & 25.80 & 6.75 & 63.15 \\
\hline & Tall & 24 & 14 & 73.68 & 74.19 & 36.84 & 93.24 \\
\hline \multirow[t]{2}{*}{ Margins } & Well defined & 78 & 3 & 15.78 & 16.12 & 3.70 & 48.38 \\
\hline & Irregular & 15 & 16 & 84.21 & 83.87 & 51.61 & 96.29 \\
\hline \multirow[t]{2}{*}{ Halo sign } & Present & 60 & 4 & 21.05 & 68.75 & 6.25 & 68.75 \\
\hline & Absent & 33 & 15 & 78.94 & 64.51 & 31.25 & 93.75 \\
\hline \multirow[t]{2}{*}{ Echogenicity } & Isoecogenicity & 43 & 5 & 26.31 & 53.76 & 10.41 & 78.12 \\
\hline & Hypoecogenicity & 50 & 14 & 73.68 & 46.23 & 25.45 & 89.58 \\
\hline \multirow[t]{2}{*}{ Homogeneity } & Present & 45 & 8 & 42.10 & 51.61 & 15.09 & 81.35 \\
\hline & Absent & 48 & 11 & 57.89 & 48.38 & 18.64 & 84.90 \\
\hline \multirow[t]{4}{*}{ Calcifications } & Microcalcification & 1 & 3 & 15.78 & 98.92 & 75.00 & 85.18 \\
\hline & Round shape & 3 & 2 & 10.52 & 95.69 & 40.00 & 83.96 \\
\hline & $\begin{array}{l}\text { Nonspecific } \\
\text { calcifications }\end{array}$ & 1 & 3 & 15.78 & 98.92 & 66.66 & 84.44 \\
\hline & Egg shell & 0 & 2 & 10.52 & 100 & 100 & 84.54 \\
\hline \multirow{2}{*}{$\begin{array}{l}\text { Extracapsular } \\
\text { invasion }\end{array}$} & Present & 0 & 8 & 42.10 & 100 & 100 & 89.42 \\
\hline & Absent & 93 & 11 & 57.89 & 0 & 10.57 & 0 \\
\hline \multirow[t]{4}{*}{ Vascularization } & Avascular & 46 & 2 & 10.52 & 49.46 & 4.08 & 73.01 \\
\hline & + Perinodular & 45 & 5 & 26.31 & 51.61 & 10.0 & 77.41 \\
\hline & Dominant vessel & 10 & 6 & 31.57 & 89.24 & 37.50 & 86.45 \\
\hline & + Intranodular & 11 & 6 & 31.57 & 88.17 & 35.29 & 86.31 \\
\hline
\end{tabular}

The diagnostic of each characteristic in differentiation between $\mathrm{BN}$ and $\mathrm{CA}$ is calculated with the ROC curve technique and presented in Fig 4. In descendent order, the characteristics are: presence of irregular margins (AUC $=0.761, \mathrm{p}=$ 0.00001 ), taller than wide (AUC $=0.723, \mathrm{p}$ $=0.0001)$, positive calcification (AUC = $0.7416, \mathrm{p}=0.0001$ ), absent halo sign (AUC $=0.717, \mathrm{p}=0.0001)$, extracapsular 
invasion (AUC $=0.684, \mathrm{p}=0.0012$ ), hypoecogenicity (AUC $=0.615, \mathrm{p}=0.0463$ ), dominant intranodular vessel (AUC = 0.609, $\mathrm{p}=0.272$ ), intranodular diffuse vascularization (AUC $=0.577, \mathrm{p}=0.0761$ ), inhomogeneity (AUC $=0.536, p=0.282$ ) and perinodular vascularization (AUC = $0.395, \mathrm{p}=0.0353$ ). The presence of at least 4 positive US 2B (multiple_2B) parameters increased the diagnostic value as compared with the isolated positive parameters: AUC $=0.8529, \mathrm{p}=0.0000$, with sensitivity =
$73.68 \%$, specificity $=96.77 \%, \mathrm{PPV}=$ $82.35 \%$ and NPV $=94.73 \%$. The best combination is positive 4 grey scale criteria, plus the presence of intranodular vascularization (dominant vessel or diffuse), described in Figure 4 as Multiple_2B-D. This association of signs shows a great AUC $=0.8995, \mathrm{p}=0.000$, with good sensitivity $=84.21 \%$, and specificity $=95.69 \%, \mathrm{PPV}=80.0 \%$ and NPV $=86.95 \%$. The results are presented in figure 4 .

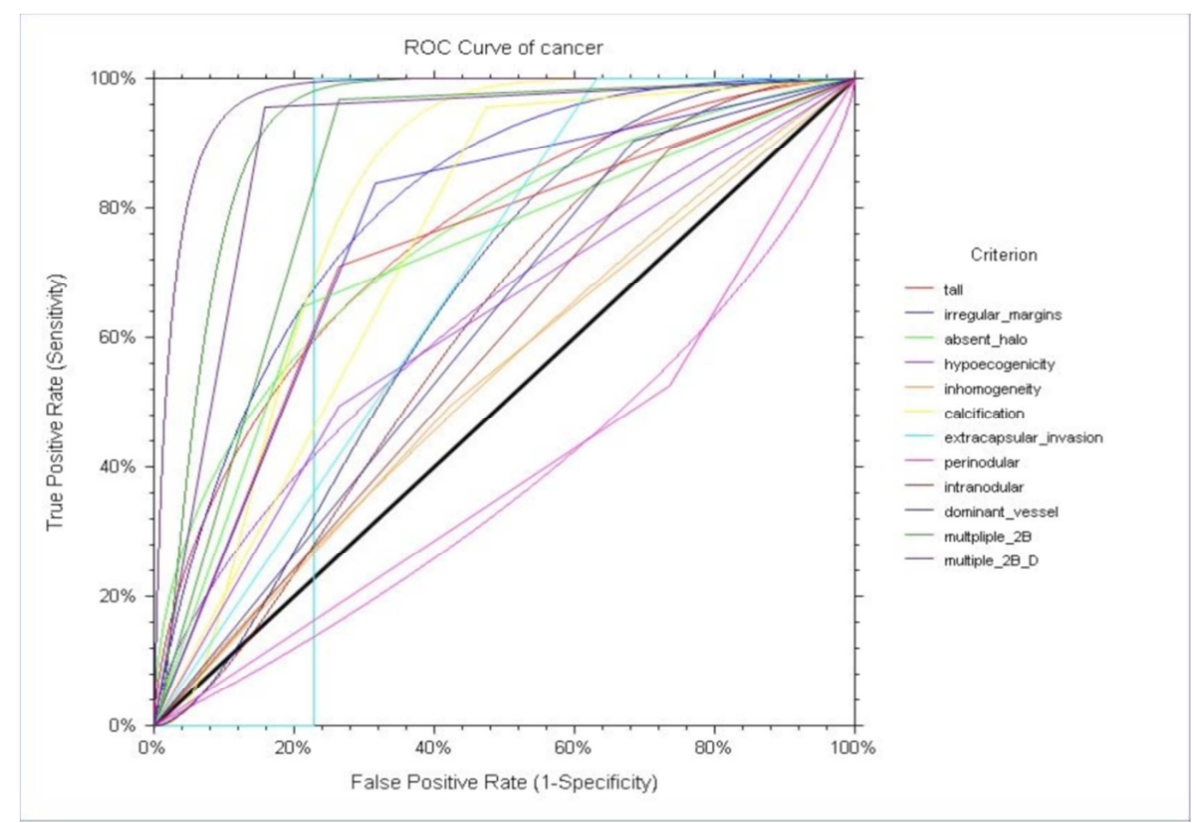

Figure 4: ROC CURVE for Grey Scale and Doppler Ultrasound Diagnostic Criteria for Evaluation Solid Nodules

There is to note the low sensitivity of the different types of calcifications but high specificity, especially of eggshell calcifications. Without being very sensitive, the calcifications are specific to malignancy.

Only intranodular hypervascularisation, diffuse or uni-vascular are predictive for malignancy, but perinodular vascularization is present both in benign and malign thyroid solid nodules.

\section{US Elastography}

When we assessed the clinical elastography: score 1 was found in 31 cases, all benign lesions and score 2 in 38 cases, also all of the benign lesions. The majority of the score 3 lesions were benign $(22 / 23)$, only 1 was found microcarcinoma at the histopathological exam. The majority of ES 4 lesions were cancers (15/17), with two anelastic nonmalignant lesions, oncitomas. All ES 5 scale lesions were thyroid cancers. The results are presented in Figure 5. 


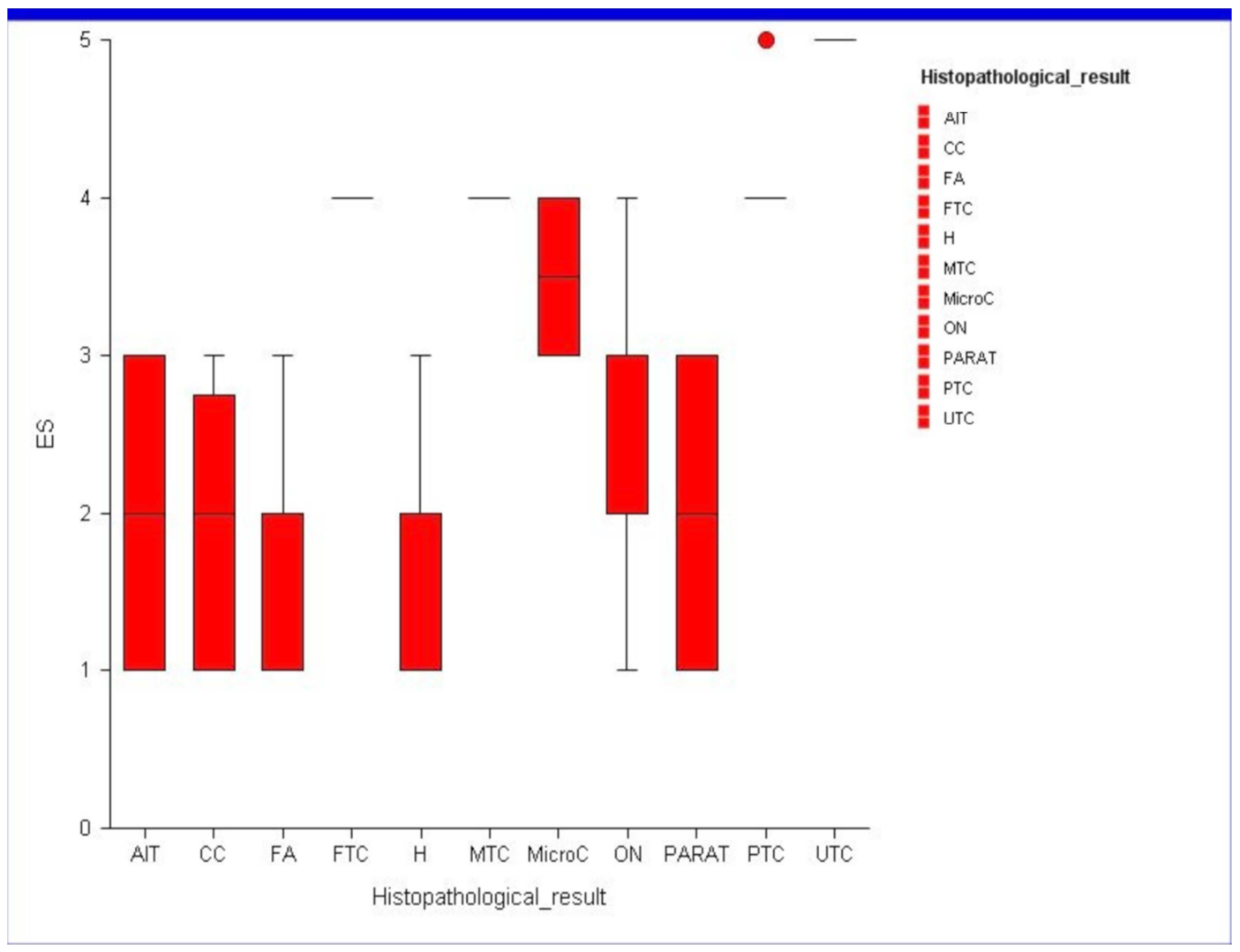

Figure 5: Distribution of RTE Color Map Results for Each Described Histopathological Entity: Autoimmune Thyroiditis (AIT), Colloid Cystic Nodules (CC), Follicular Adenoma (FA), Hyper Functioning Adenomas (H), Oxyphilic Adenomas (ON), Parathyroid Lesions (PARAT), Microc (Microcarcinoma), FTC (Follicular Thyroid Carcinoma), MTC (Medullar Thyroid Carcinoma), PTC (Papillary Thyroid Carcinoma) and UTC (Undifferentiated Thyroid Carcinoma).

The diagnostic power of each ES value was calculated for the entire group, high ES score having high diagnostic value for cancer, and low ES score having high diagnostic value for benign condition. The results are present in TABLE 3.

Table 3: Predictive Value of Us Elastography in Patients with Histopathological Diagnostic

\begin{tabular}{|l|l|l|l|l|}
\hline Score & $\begin{array}{l}\text { sensitivity } \\
(\%)\end{array}$ & $\begin{array}{l}\text { specificity } \\
(\%)\end{array}$ & $\begin{array}{l}\text { PPV } \\
(\%)\end{array}$ & $\begin{array}{l}\text { NPV } \\
(\%)\end{array}$ \\
\hline ES 1 for benign condition & 33.33 & 100 & 100 & 23.45 \\
\hline ES 2 for benign condition & 40.86 & 100 & 100 & 25.67 \\
\hline ES 3 for benign condition & 23.65 & 94.73 & 95.56 & 20.22 \\
\hline ES 1-3 for benign condition & $\mathbf{9 7 . 8 4}$ & $\mathbf{8 9 . 4 7}$ & $\mathbf{9 7 . 8 4}$ & $\mathbf{8 9 . 4 7}$ \\
\hline ES 4 for cancer & 78.94 & 97.84 & 88.28 & 95.78 \\
\hline ES 5 for cancer & 15.78 & 100 & 100 & 85.32 \\
\hline ES 4-5 for cancer & $\mathbf{8 9 . 4 7}$ & $\mathbf{1 0 0}$ & $\mathbf{1 0 0}$ & $\mathbf{9 7 . 8 9}$ \\
\hline
\end{tabular}




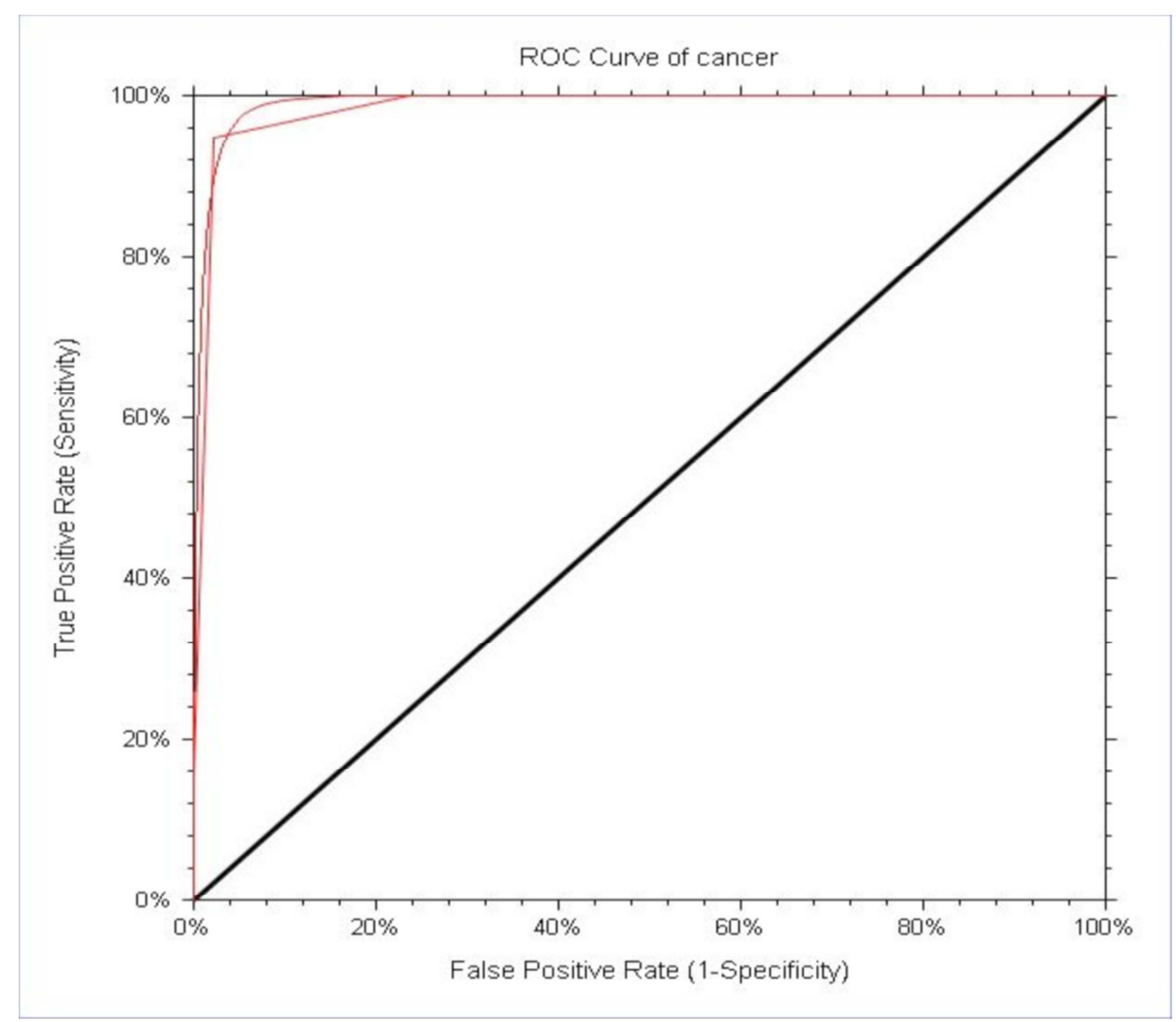

Figure 6: ROC Method to Evaluate Qualitative RTE Method in Diagnosing Solitary Solid Thyroid Nodules

There is to remark that other diagnostic tools have high specificity but low sensitivity (extracapsular extension, eggshell calcification, microcalcifications) or high sensitivity with low specificity (absent halo sign, hypoecogenicity). We analyzed the quality of qualitative elastography evaluation and we observed that the AUC of the ROC curve was very high, of 0.99108. $\mathrm{p}=0.00001$ - Figure 6 . The diagnostic quality outreached the other ultrasound evaluation, even the positive combined criteria very much.

The false positive results for malignancy were two cases with oncocytic lesions. These benign lesions appeared to be malignant, due to hypoecogenicity, increased intranodular vascularization and a pattern 4 of RTE. They did not show extracapsular extension and did not present any calcifications.
Microcarcinoma appeared to be benign because only a portion of the nodule was with increased strain.

\section{Discussion}

The paper of Ophir et al. (1999) explains the principle of elastography, as an extended ultrasound dynamic technique that uses tissue rigidity/elasticity modulus $=$ Young modulus for differentiating elasticity/anelasticity of the nodules. The strain ration technique, that our group used, evaluates, as recommended in the literature, Yourong et al. (2009), the degree of distortion of a tissue under the application of a controlled external force, measuring differences between different tissue elasticity. 
We used the monitoring of the freehand applied compression by the standardized real-time measurement on a numerical scale, provided by the US machine, which a moderate pressure of 3-4 on the selfevaluation pressure scale of the Hitachi device. This technique is easy to perform, in real time, in the same session, and minimized the artifacts generated by the applied external pressure as described Asteria et al. (20108) and in the opinion of some authors, by the EFSMUB Guidleines (2013) might substitute FNAB in the future, especially in small or difficult to punction lesions, as we saw in a previous study (2012).

Almost all high ES score we observed, 4 and 5 , were described in cancer cases. The false negative results were 1 case with big nodule and microcarcinoma, that was assigned to score 3 lesions, because, with o portion of nodule with hard density, and a carcinoma presented in a big nodule, that also was assessed as ES $=3$. Our results showed a high sensitivity for high ES score in cancer detection (89.47\%) comparable with those described in the literature, in the papers of Corgrove et al (2013), Yourong et al. (2009), Vorlander et al ( 2010), Cantisani et al. (2012) and Ning et al. (2012). The high sensitivity is achieved without a decrease in the specificity of the diagnostic, as we saw in when we compared the area under ROC curve in qualitative elastography (99.10\%) versus conventional ultrasound (85.29\%) and Doppler technique (55.70\%) alone or combined with the conventional US (89.95\%). These good values are influenced also by the inclusion criteria; only solid/almost solid lesions were included in the study. It is known, as described by Bojunga et al (2010) and Bamber et al. (2013) that high proportion of cystic lesions and calcification affect the diagnostic accuracy, explained by Lipollis et al (2011) by the direct influence of the elastic force transmission.

In our patient cohort, low ES values are almost $100 \%$ diagnostic criteria for benign lesions. We did not see any thyroid cancer with low color map scale (1 and 2) in RTE. These results are similar with the data from the literature, reported by us in previous data, Stoian et al. (2012, 2013), but also from Yourong $\mathrm{H}$ et al. (2009), Vorlader et al. (2010), Rubatelli et al. (2009), Wang et al (2010).

High anelasticity scores (ES 4 and 5) are highly predictive for malignant lesions. These characteristics are responsible for high diagnostic accuracy for the real-time elastography method, as reported in Rubetelli's paper in 2009.

Some studies recommend caution in cases with microcarcinoma: Gao et al. (2011), Bamber et al. (2013), and Kim et al. (2012), remains a pitfall diagnostic in elastography, because the assessment is made for the total nodular color aspect, although, in big nodules there is often seen important differences in elasticity. We saw this phenomenon also in our study, where one of the two identified microcarcinoma had an ES 3 score.

Generally, ES 3 score are predictive for benign lesions, but possible microcarcinoma should be kept in mind as reported in Kim's et al. (2012) and Cantisani's paper (2012).

We observed that there is a difference between ES in hyperplastic and oxyphilic adenoma compared with follicular or anisofollicular benign lesions, but further studies, with high number of cases, are needed for a precise conclusion.

US elastography should be used in differentiating cases with solitary thyroid nodules. Total thyroidectomy in cases with high elastography score ( 4 and 5 ) should be performed because the number of false positive cases is very low. Cantisani et al. (2012) suggest that elastography, helps deciding when and what to operate, in cases with solitary nodule.

The threshold of strain ratio remains the great problem of elastography. There is no consensus of which value should be used to correct identify benign versus malignant nodules. Proposed values are, by Park (2008) between 2 and 3 are used (28), mean of $2.9 \pm 0.8$, with good diagnostic 
values: sensitivity $=70.6 \%$, specificity $=$ $85.2 \%$. Cutoff values of 3-4are recommended by Itoh's group (2006), with a sensitivity of $91 \%$, specificity of $89 \%$, PPV $94 \%$ and NPV $85 \%$ (29). But, conversely, the same cutoff values Lipollos's paper shows, in selected population, with intermediate cellularity, low PPV, of $34 \%$ with low NPV< of $50 \%$. These data come in great controversy with other studies, with good results: Park (2008), Ioth et al. (2006), Ning et al. (2012), and Wang et al. (2010),where values higher than 2 where used. It is clear that more data are needed to clarify this matter.

\section{Conclusions}

Real time elastography is a useful tool in differentiating the solitary thyroid nodules. In cases with intermediate cytological results, small lesions and difficult nodules or in noncompliant patients, the information obtained, form the real time elastography should be used. Regardless, conventional US results and Doppler findings, a very high ES score (4 or 5) has to be considered suggestive for malignancy.

\section{References}

1. Lazar, F. (2008). 'Thyroid Surgical Pathology, in Textbook of Surgery, Irinelpopescu, Edit Academieiromane,' Bucuresti 803-836 "In Romanian"

2. Ghelase, F., Bistriceanu, M., Georgescu, I., Ghelasem, Gaban, V. et al. (2007). 'Differentiated Thyroid Carcinoma. Diagnostic and Therapeutical Aspects,' $\begin{array}{llll}\text { Chirurgia } & 102 & \text { (3) 289-295 "In }\end{array}$ Romania"

3. Hegedus, L. (2004). "Clinical Practice: The Thyroid Nodule," New England Journal of Medicine. 351 1764-1771

4. Frates, M. C., Benson, C. B., Charnoneau, J. W., Cibas, E. S., Clark, O. H., Colemanbg, B. G.et al. (2005). "Management of Thyroid Nodules Detected at US: Society of Radiologists in Ultrasound Consensus Conference Statement," Radiology 237 794-800
5. Harach, H. R., Fransilla, K. O. \& Wasenius, V. M. (1985). "Occult Papillary Carcinoma of the Thyroid. A "Normal" Finding in Finland. A Systematic Autopsy Study," Cancer 56 531-538

6. Papini, E. (2003). "The Dilemma of Non-Palpable Thyroid Nodules," Journal of Endocrinological Investigation. 26 3-4

7. Tan, G. H., Gharib, H. \& Reading, C. C. (1995). "Solitary Thyroid Nodule: Comparison between Palpation and Ultrasonography," Archives of Internal Medicine. 155 2418-2423

8. Moon, W. J., Baek, J. H., Jung, S. L., Kin, D. W., Kim, E. K. et al. (2011). "Ultrasound and the Ultrasound-Based Management of Thyroid Nodules: Consensus Statement and Recommendations," Thyroid Study Group of Korean Society of Radiology (TSGKSR). Korean Journal of Radiology 1291 1-14

9. American Thyroid Association (ATA) Guidelines Taskforce on Thyroid Nodules and Differential Thyroid Cancer. (2009). Revised ATA Guidelines for Patients with Thyroid Nodules and Differentiated Thyroid Cancer. Thyroid 19 1167-1214

10. Gharib, H., Papini, E., Valcali, R., Bhashin, H. J., Crescenzi, A., Dottorini, M. E. et al. (2006). "American Association of Clinical Endocrinologist and Associazone Medici Endocrinologi: Medical Guidelines for Future Practice for Diagnosis and Management of Thyroid Nodules," Endocrine Practice 12 63-102

11. Leenhardt, L., Traquart, F. \& Tramalloni, J. (2011). "Advances in Thyroid Ultrasound for Detection and Follow-Up of Thyroid Malignancies. Technical and Clinical Aspects," Ch 8 in Thyroid Cancer Jeffrey Mechanick, CRC Press, 100-116. 
12. Stoian, D., Corneanu, M., Dobrescu, A. \& Lazar, F. (2012). "Nodular Thyroid Cancer. Diagnostic Value of Real Time Elastography," Chirurgia (Bucur) 107 (1) 39-46.

13. Cosgrove, D., Psicaglia, F., Bamber, J., Correas, J.- M. et al. (2013). "EFSUMB Guidelines and Recommendations of the Clinical Use of Ultrasound Elastography. Part 2: Clinical Applications," Guidelines of ESFMUB, Ultraschall in Med 34 238-25

14. Asteria, C., Giovanardi, A., Pizzocaro, A. et al. (2008). "US-Elastographyin the Differential Diagnosis of Benign and Malignant Thyroid Nodules," Thyroid 18 523-531

15. Rago, T., Santini, F., Scutari, M., Pinchera, A. \& Vitti, P. (2007). "Elastography: New Developments in Ultrasound for Predicting Malignancy in Thyroid Nodules," The Journal of Clinical Endocrinology \& Metabolism. 92:2917-2922

16. Bojunga, J., Herrmann, E., Meyer, G. et al. (2010). "Real-Time Elastography for the Differentiation of Benign and Malignant Thyroid Nodules: A MetaAnalysis," Thyroid 20 1145-1150

17. Lippolis, P. V., Tognini, S., Materazzi, G. et al. (2011). "Is Elastography Actually Useful in the Presurgical Selection of Thyroid Nodules with Indeterminate Cytology?," The Journal of Clinical Endocrinology \& Metabolism, 96 E1826-1830

18. Gao, J., Kazam, J. K. \& Kazam, E. (2011). Multimodality Imaging and Aspiration Biopsy Guidance in the Perioperative Management of Thyroid Carcinoma. in Thyroid Cancer, Jeffrey Mechanick. CRC Press, 100-116.

19. Bamber. J., Cosgrove, D., Dietrich, C. F., Fromageau, J. et el. (2013). "EFSUMB Guidelines and Recommendations of the Clinical Use of Ultrasound Elastography. Part 1: Basic Principles and Technology," Ultraschall in Med. 34 169-184

20. Heidinger, C. H. R. \& Sobin, L. H. (1974). 'Histological Typing of Thyroid Tumors,' in: World Health Organization. International Histological Classification of Tumors. Geneva: Rotosatag AS.17-27

21. Ophir, J., Alam, S. K., Garra, B., Kallel, F., Knofagou, E., Krouskop, T. \& Varghese, T. (1999). "Elastography: Ultrasonic Estimation and Imaging of the Elastic Proprieties of Tissue," Proceedings of the Institution of Mechanical Engineers, Part H: Journal of Engineering in Medicine, 213 203-233.

22. Hong, Y., Liu, X., Li, Z., Zhang, X., Chen, M. \& Luo, Z. (2009). "Real-Time Ultrasound Elastography in the Differential Diagnosis of Benign and Malignant Thyroid Nodules," Journal of Ultrasound in Medicine: Official Journal of the American Institute of Ultrasound in Medicine. 28 861-86

23. Stoiand, Lazar, F., Craciunescu, M. \& Craina, M. (2013). 'Strain Ration Calculation - Diagnostic Value in Malignant Uninodular Thyroid Cancer,' Presented at the 22nd AACE Annual Meeting, 1-5 May, Phoenix, USA

24. Vorlander, C., Wolff, J., Saalbanian, S. et al. (2010). "Real-Time Elastography- A Noninvasive Diagnostic Procedure for Evaluating Dominant Thyroid Nodules," Langenbeck's Archives of Surgery, 395 865-871

25. Rubatelli, L., Corradin, S., Dorigo, A., Stabilito, M., Tregnaghi, A., Borsato, S. \& Stramare, R. (2009). "Differential Diagnosis of Benign and Malignant Thyroid Nodules at Elastography," Ultraschall in der Medizin. 30 (2) 175179.

26. Kim, J. K., Baek, J. H., Lee, J. H. et al. (2012). "Ultrasound Elastography for Thyroid Nodules: A Reliable Study?," Ultrasound in Medicine and Biology, 38 1508-1513 
27. Cantisani, V., Ulisse, S., Guataitoli, E. et al. (2012). "Q-Elastography in the Presurgical Diagnosis of Thyroid Nodules with Indeterminate Cytology," PLoS One 7: E5072

28. Jean Seon Park (2008). 'The Ultrasound Elastography for the Indeterminate Thyroid Nodules in Conventional Ultrasound,' Radiological Society of North America 94th Scientific Assembly and Annual Meeting in November 30th -December 5th, Chicago, USA

29. Itoh, A., Ueno, E., Tohno, E. et al. (2006). "Breast Disease: Clinical Application of US Elastography for Diagnosis," Radiology 239 341-350
30. Ning, C. P., Jiang, S. Q., Zhang, T. et al. (2012). "The Value of Strain Ratio in Differential Diagnosis of Thyroid Solid Nodules," European Journal of Radiology, 81 286-291

31. Wang, Y., Dan, H. J., Dan, H. Y. et al. (2010). "Differential Diagnosis of Small Single Solid Thyroid Nodules Using Real-Time Ultrasound Elastography," Journal of International Medical Research 38 466-472 